\title{
QUANTIFICATION OF THE OPERATOR PROXIMITY EFFECT ON THE MEASUREMENT RESULTS OF ELECTRIC FIELD STRENGTH IN THE VICINITY OF OVERHEAD POWER LINES
}

\author{
Maja Grbić* ${ }^{*}$ Aleksandar Pavlović \\ University of Belgrade, Nikola Tesla Electrical Engineering Institute, Belgrade, Serbia
}

\begin{abstract}
In this paper, the operator proximity effect on the measurement results of the electric field strength in the vicinity of overhead power lines is analyzed. The operator proximity effect depends on the distance between the operator and the probe for measuring the electric field strength, as well as on the height at which the probe is placed. The paper presents the results of the electric field strength measurements performed in the vicinity of a $220 \mathrm{kV}$ overhead power line in order to quantify the influence of the proximity of the operator. The measurements were carried out by using a cube-shaped isotropic probe. During the measurements, the probe was placed on a wooden tripod and connected to the electromagnetic field analyzer by an optical cable. The measurements were performed at the heights of $1 \mathrm{~m}, 1.5 \mathrm{~m}$ and $1.7 \mathrm{~m}$. The distance between the operator and the measuring probe during these measurements was gradually increased from $1 \mathrm{~m}$ to $10 \mathrm{~m}$. The obtained results are analyzed in detail in this paper. These results can be used for evaluating the electric field strength measurement uncertainty. The significance of these results also lies in demonstrating the manner in which the operator's influence on the measured field can be reduced to an acceptable level.
\end{abstract}

Key words: Electric field strength, operator proximity effect, overhead power line, measurement, non-ionizing radiation.

\section{INTRODUCTION}

The presence of the operator, i.e. a person who performs measurements, causes the electric field perturbation. Therefore, the results of electric field strength measurements are influenced by the proximity of the operator $[1,2]$. The influence of the operator's presence on the results of electric field strength measurements has to be taken into account when calculating the expanded measurement uncertainty. For that reason, the quantification of this influence is of great importance. It is also important for providing recommendations for its reduction to an acceptable level.

The operator proximity effect depends on the distance between the operator and the probe for electric field strength measurements, as well as on the height at which the probe is placed. The influence decreases with the increase of distance between the operator and the measuring probe. Therefore, in order to reduce the influence of the operator, the measuring probe is usually placed on a tripod and connected to the measuring device by a several-meter-long optical cable.

In order to quantify the influence of the proximity of the operator on electric field strength measurement results, extensive field measurements were performed in the vicinity of a $220 \mathrm{kV}$ overhead power line.

\section{ELECTRIC FIELD STRENGTH MEASUREMENTS}

\subsection{Measuring equipment}

The measurements were performed by using Narda Safety Test Solutions EFA-30o electromagnetic field analyzer connected to an isotropic probe for electric field strength measurements [3]. This probe ensures simultaneous measurements of all three spatial components of the electric field vector, based on which the instrument shows their resultant value $(E)$. The probe is cube-shaped, with a $10 \mathrm{~cm}$ edge. During the measurements, the probe was placed on a wooden tripod and connected to the analyzer by a $10 \mathrm{~m}$ long optical cable.

\subsection{Measurement location}

The measurements were performed in the vicinity of the $220 \mathrm{kV}$ overhead power line No. 278, between the towers 9 and 10. The tower 9 is presented in Figure 1. The disposition of the phase conductors is horizontal. The heights of the phase conductors and ground wires and distances between them are given in Table 1 , where symbols denote the following:

$h_{p}[\mathrm{~m}]$ - height of phase conductor,

$h_{g}[\mathrm{~m}]$ - height of ground wire,

$d_{p}[\mathrm{~m}]$ - distance between phase conductors,

$d_{g}[\mathrm{~m}]$ - distance between ground wires.

*maja.grbic@ieent.org 
In Figure 1 and Table 1, phase conductors are indicated as 0,4 and 8, and ground wires as 1 and 2 .

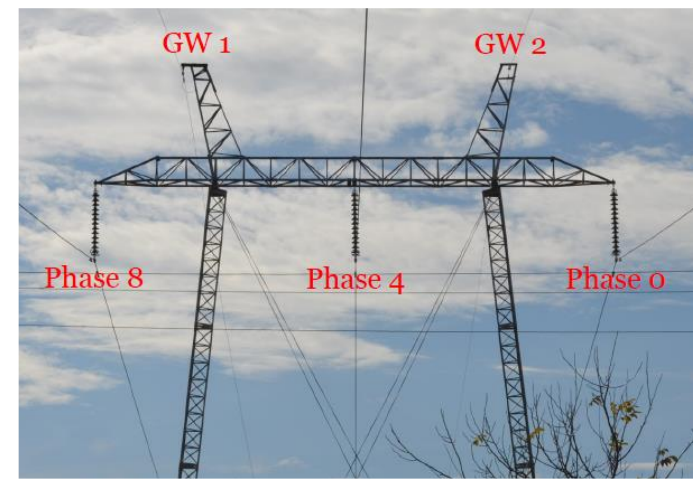

Figure 1. Power line tower at the span where electric field measurements were performed

Table 1. Heights of the phase conductors and ground wires and distances between them

\begin{tabular}{|c|c|c|c|}
\hline$h_{p}[\mathrm{~m}]$ & $d_{p}[\mathrm{~m}]$ & $h_{g}[\mathrm{~m}]$ & $d_{g}[\mathrm{~m}]$ \\
\hline 0: $9.0 \mathrm{~m}$ & $0-4: 8.5 \mathrm{~m}$ & $1: 18.2 \mathrm{~m}$ & $1-2: 10.4 \mathrm{~m}$ \\
$4: 8.9 \mathrm{~m}$ & $4-8: 8.5 \mathrm{~m}$ & $2: 18.3 \mathrm{~m}$ & \\
$8: 9.3 \mathrm{~m}$ & & \\
\hline
\end{tabular}

In order to avoid the influence of different objects on electric field distribution, the location without any objects that could affect the levels of electric field strength was chosen. The measurements were performed on a flat terrain, along the lateral profile located $132 \mathrm{~m}$ from the tower 9 and $193 \mathrm{~m}$ from the tower 10 .

\subsection{Measurement procedure}

The measurements were performed at a large number of measuring points along the lateral profile (perpendicular to the power line axis) according to [4-6]. In order to quantify the operator proximity effect, the measurements were carried out by gradually increasing the distance between the operator and the probe $(d)$ from $1 \mathrm{~m}$ to $10 \mathrm{~m}$. The testing was done by an operator $1.7 \mathrm{~m}$ tall.

\section{MEASUREMENT RESULTS}

3.1. Measurements along the lateral profile at the height of $1 \mathrm{~m}$ above ground

Initially, the measurements were performed along the lateral profile at the height $(h)$ of $1 \mathrm{~m}$ above ground. At each point, the measurements were performed with distances of $1 \mathrm{~m}, 2 \mathrm{~m}, 3 \mathrm{~m}, 4 \mathrm{~m}, 5 \mathrm{~m}$ and $10 \mathrm{~m}$ between the operator and the measuring probe. The measurements were performed in direction of $x$ axis, while the operator was standing at the same measurement profile behind the probe.

The obtained results are presented in Table 2 and Figure 2, where symbols denote the following:

$n$-ordinal number of the measurement point along the measurement profile, $x[\mathrm{~m}]-$ horizontal distance between the power line axis and the measurement point,

$E[\mathrm{kV} / \mathrm{m}]$ - measured value of electric field strength.

Table 2. Values of electric field strength $E[\mathrm{kV} / \mathrm{m}]$ obtained by measurements along the lateral profile with different distances between the operator and the measuring probe

\begin{tabular}{|c|c|c|c|c|c|c|c|}
\hline \multirow{2}{*}{$n$} & \multirow{2}{*}{$x[\mathrm{~m}]$} & \multicolumn{6}{|c|}{$d[\mathrm{~m}]$} \\
\cline { 3 - 8 } & & $1 \mathrm{~m}$ & $2 \mathrm{~m}$ & $3 \mathrm{~m}$ & $4 \mathrm{~m}$ & $5 \mathrm{~m}$ & $10 \mathrm{~m}$ \\
\hline 1 & -30 & 0.393 & 0.406 & 0.409 & 0.414 & 0.417 & 0.418 \\
\hline 2 & -25 & 0.686 & 0.710 & 0.711 & 0.721 & 0.722 & 0.724 \\
\hline 3 & -20 & 1.159 & 1.205 & 1.210 & 1.224 & 1.212 & 1.220 \\
\hline 4 & -18 & 1.433 & 1.506 & 1.501 & 1.530 & 1.535 & 1.533 \\
\hline 5 & -16 & 1.760 & 1.835 & 1.855 & 1.876 & 1.866 & 1.869 \\
\hline 6 & -14 & 2.359 & 2.489 & 2.490 & 2.522 & 2.514 & 2.519 \\
\hline 7 & -12 & 2.627 & 2.748 & 2.776 & 2.814 & 2.812 & 2.803 \\
\hline 8 & -10 & 2.649 & 2.819 & 2.862 & 2.909 & 2.905 & 2.914 \\
\hline 9 & -8 & 2.481 & 2.662 & 2.711 & 2.754 & 2.759 & 2.742 \\
\hline 10 & -6 & 2.051 & 2.210 & 2.265 & 2.306 & 2.303 & 2.315 \\
\hline 11 & -4 & 1.903 & 2.022 & 2.055 & 2.081 & 2.083 & 2.089 \\
\hline 12 & -2 & 1.903 & 2.030 & 2.061 & 2.081 & 2.075 & 2.075 \\
\hline 13 & 0 & 2.014 & 2.145 & 2.172 & 2.206 & 2.202 & 2.186 \\
\hline 14 & 2 & 1.920 & 2.048 & 2.087 & 2.122 & 2.115 & 2.120 \\
\hline 15 & 4 & 1.829 & 1.951 & 1.977 & 2.010 & 1.998 & 2.004 \\
\hline 16 & 6 & 2.121 & 2.229 & 2.245 & 2.276 & 2.265 & 2.266 \\
\hline 17 & 8 & 2.537 & 2.683 & 2.794 & 2.818 & 2.811 & 2.813 \\
\hline 18 & 10 & 2.796 & 2.948 & 2.999 & 3.024 & 3.022 & 3.022 \\
\hline 19 & 12 & 2.643 & 2.795 & 2.857 & 2.890 & 2.875 & 2.894 \\
\hline 20 & 14 & 2.312 & 2.461 & 2.525 & 2.562 & 2.551 & 2.568 \\
\hline 21 & 16 & 1.889 & 2.040 & 2.079 & 2.101 & 2.120 & 2.132 \\
\hline 22 & 18 & 1.495 & 1.625 & 1.655 & 1.676 & 1.685 & 1.698 \\
\hline 23 & 20 & 1.196 & 1.266 & 1.296 & 1.297 & 1.321 & 1.331 \\
\hline 24 & 25 & 0.645 & 0.691 & 0.705 & 0.709 & 0.714 & 0.718 \\
\hline 25 & 30 & 0.382 & 0.408 & 0.414 & 0.418 & 0.420 & 0.422 \\
\hline & & & & & & & \\
\hline
\end{tabular}

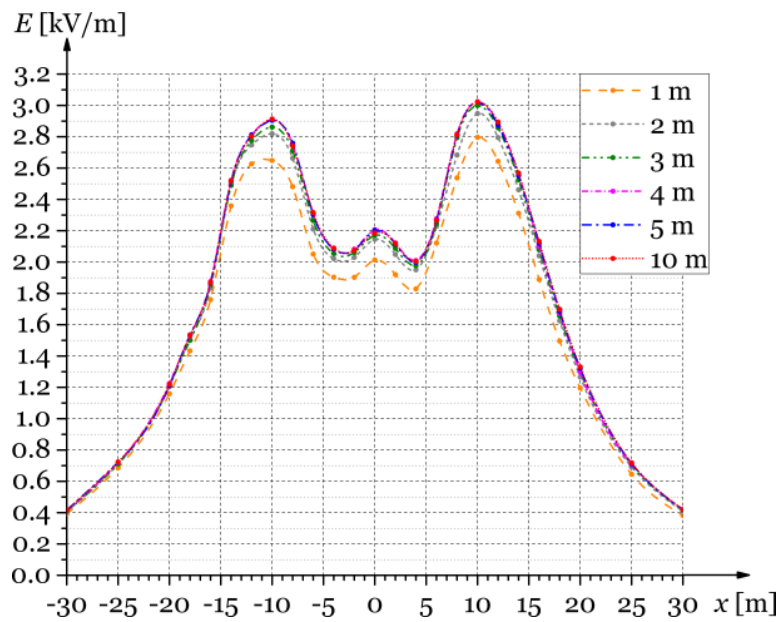

Figure 2. Electric field distributions along the lateral profile obtained for different distances between the operator and the measuring probe

For calculating the error in the electric field strength measurements $(\delta)$ due to the presence of the 
operator, the values obtained for $d=10 \mathrm{~m}$ are considered to be true values $\left(E_{t}\right)$. Values $E_{i}$ obtained for the distances $i=1 \mathrm{~m}, 2 \mathrm{~m}, 3 \mathrm{~m}, 4 \mathrm{~m}, 5 \mathrm{~m}$ contain an error $\delta_{i}$ due to the presence of the operator. This error is calculated as:

$$
\delta_{i}[\%]=\frac{E_{i}-E_{t}}{E_{t}} \cdot 100
$$

The calculated values of errors $\delta_{i}$ for distances of $1 \mathrm{~m}, 2 \mathrm{~m}, 3 \mathrm{~m}, 4 \mathrm{~m}$ and $5 \mathrm{~m}$ between the operator and the probe are given in Figures 3-7, respectively.

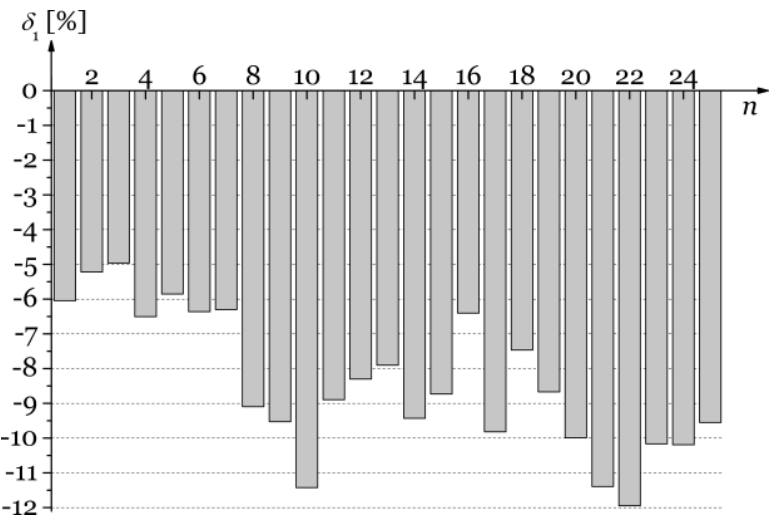

Figure 3. Percent errors for $d=1 \mathrm{~m}, h=1 \mathrm{~m}$

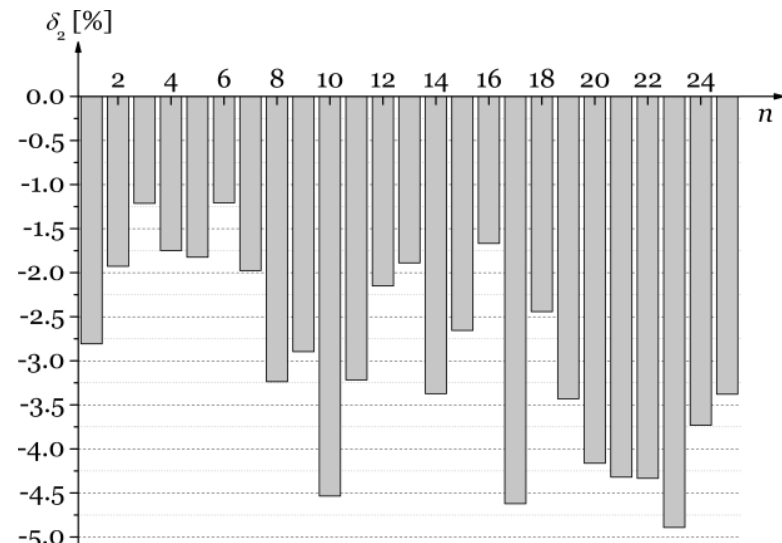

Figure 4. Percent errors for $d=2 \mathrm{~m}, h=1 \mathrm{~m}$

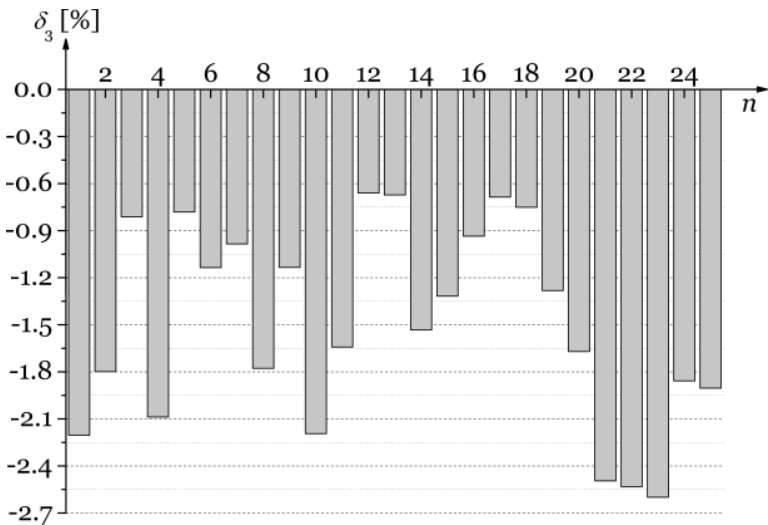

Figure 5. Percent errors for $d=3 \mathrm{~m}, h=1 \mathrm{~m}$

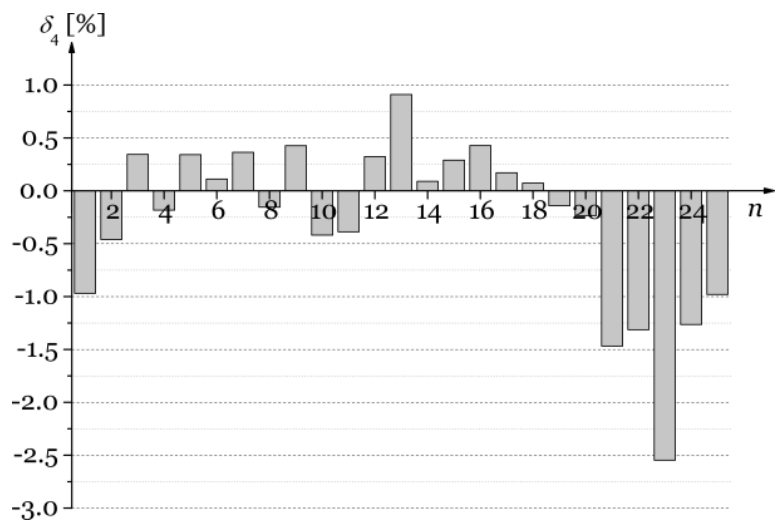

Figure 6. Percent errors for $d=4 \mathrm{~m}, h=1 \mathrm{~m}$

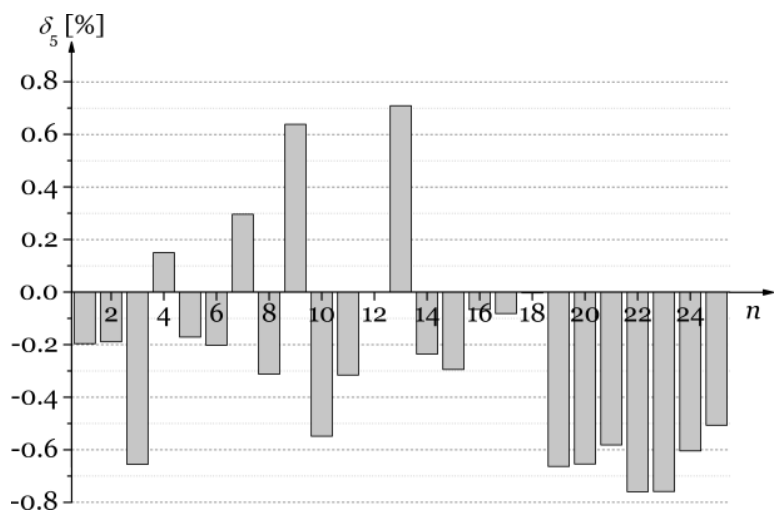

Figure 7. Percent errors for $d=5 \mathrm{~m}, h=1 \mathrm{~m}$

Figure 8 presents error ranges for each distance between the operator and the probe, which encompass the errors corresponding to all the measuring points along the lateral profile.

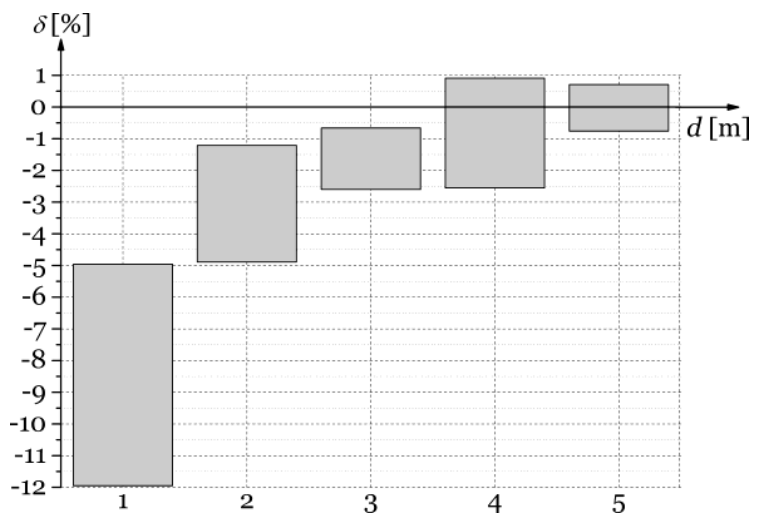

Figure 8. Ranges of percent errors $\delta$ for different values of $d$

3.2. Measurements at the heights of $1 \mathrm{~m}, 1.5 \mathrm{~m}$ and $1.7 \mathrm{~m}$ above ground at the point of the maximum field level

The measurements performed at the height of $1 \mathrm{~m}$ above ground showed that the maximum value of electric field strength was obtained at $x=10 \mathrm{~m}$, at the measurement point No. 18. At this point, more detailed measurements were carried out at the heights of $1 \mathrm{~m}$, $1.5 \mathrm{~m}$ and $1.7 \mathrm{~m}$ above ground. During the entire measurement procedure, the probe was placed at the 
position $x=10 \mathrm{~m}$. The measurements were performed by increasing the distance between the operator and the measuring probe in $1 \mathrm{~m}$ increments, from the initial distance of $1 \mathrm{~m}$ until the final distance of $10 \mathrm{~m}$. In order to obtain the most accurate results, 10 measurements of electric field strength were performed at each distance and height and the average value of these 10 results was calculated. These average values were used in further analysis. During the measurements the operator was standing at the same lateral profile where the measuring probe was located, at a greater distance from the power line axis than the probe.

The electric field strength measurement results obtained when the probe was placed at the height of $1 \mathrm{~m}$ are shown in Figure 9.

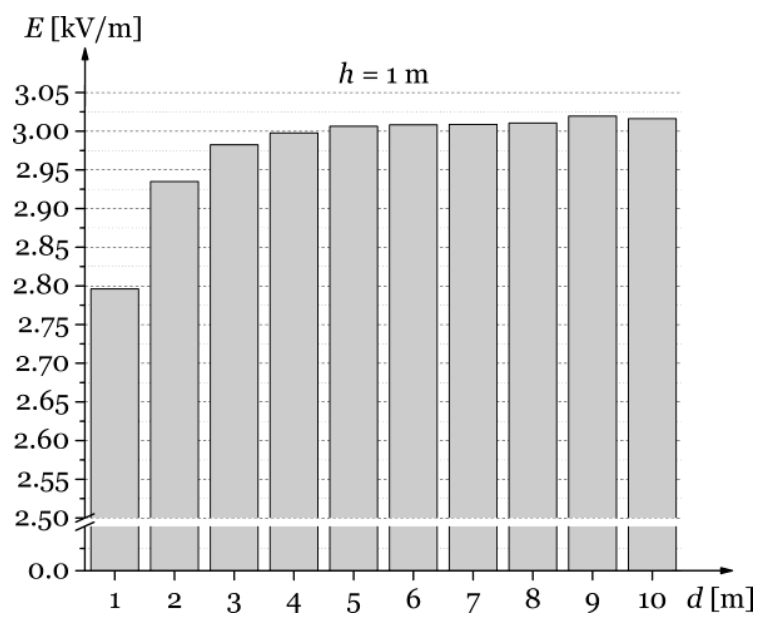

Figure 9. Measured values of electric field strength at $h=1 \mathrm{~m}$

In Figure 9 it can be observed that lower field values were obtained at shorter distances between the operator and the probe, compared to the true field value, which corresponds to $d=10 \mathrm{~m}$. The influence of the operator significantly decreases at distances greater than $5 \mathrm{~m}$.

The results obtained for the cases when the probe was placed at the heights of $1.5 \mathrm{~m}$ and $1.7 \mathrm{~m}$ are shown in Figures 10 and 11, respectively.

As it can be seen in Figures 10 and 11, the values of electric filed strength at the distance of $1 \mathrm{~m}$ were higher than the true ones. For the height of $1.5 \mathrm{~m}$, the field values obtained at the distances between $2 \mathrm{~m}$ and $5 \mathrm{~m}$ were slightly lower compared to the true values. For the height of $1.7 \mathrm{~m}$, the same is true for the distances of $2 \mathrm{~m}$ and $3 \mathrm{~m}$.

Percent errors were calculated for all the results presented in Figures 9-11. It was assumed that the true value of the electric field strength was the one measured with the $10 \mathrm{~m}$ distance between the operator and the probe. All percent errors were calculated with reference to that value. The calculated percent errors are given in Table 3 and Figure 12.

As it can be seen from Figure 12, the calculated percent errors are in accordance with the results given in [2]. At distances of $5 \mathrm{~m}$ and greater, the values of percent error are lower than $0.5 \%$ regardless of the height at which the measuring probe is placed. On the basis of the presented results it can be concluded that the distance between the operator and the measuring probe of $3 \mathrm{~m}$, recommended in [5], is sufficient to provide the reduction of this influence to an acceptable level, since the percent errors $\delta$ given in Table 3 are in that case lower than $\mathbf{1 . 2} \%$ for all three analyzed probe heights.

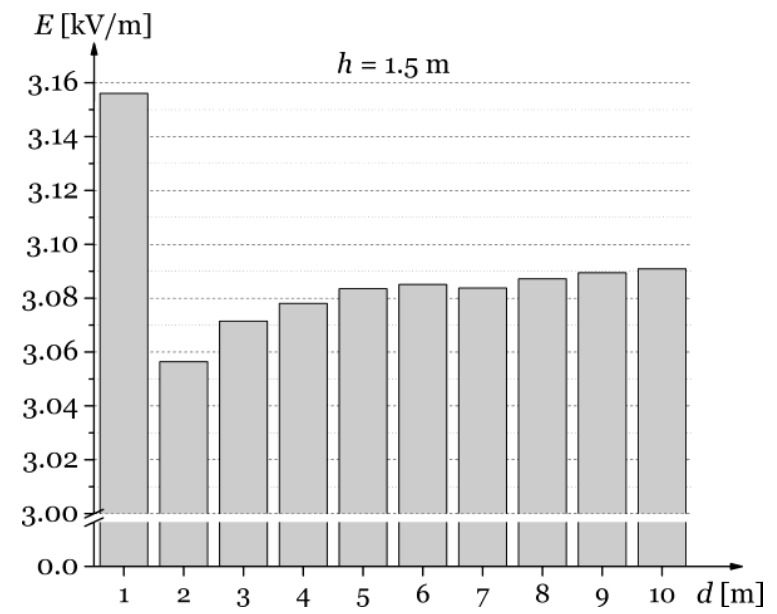

Figure 10. Measured values of electric field strength at $h=1.5 \mathrm{~m}$

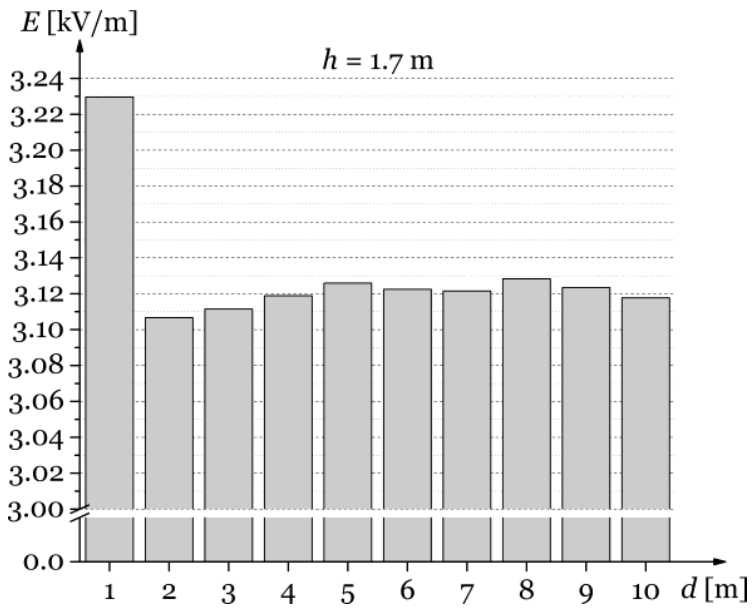

Figure 11. Measured values of electric field strength at $h=1.7 \mathrm{~m}$

Table 3. Percent errors for various distances between the measuring probe and the operator and different heights of the measuring probe

\begin{tabular}{|c|c|c|c|}
\hline \multirow{2}{*}{$d[\mathrm{~m}]$} & \multicolumn{3}{|c|}{$\delta[\%]$} \\
\cline { 2 - 4 } & $h=1 \mathrm{~m}$ & $h=1.5 \mathrm{~m}$ & $h=1.7 \mathrm{~m}$ \\
\hline 1 & -7.297 & 2.108 & 3.587 \\
\hline 2 & -2.695 & -1.116 & -0.355 \\
\hline 3 & -1.116 & -0.628 & -0.200 \\
\hline 4 & -0.613 & -0.415 & 0.038 \\
\hline 5 & -0.325 & -0.239 & 0.263 \\
\hline 6 & -0.262 & -0.188 & 0.153 \\
\hline 7 & -0.246 & -0.231 & 0.122 \\
\hline 8 & -0.186 & -0.120 & 0.342 \\
\hline 9 & 0.112 & -0.048 & 0.182 \\
\hline
\end{tabular}




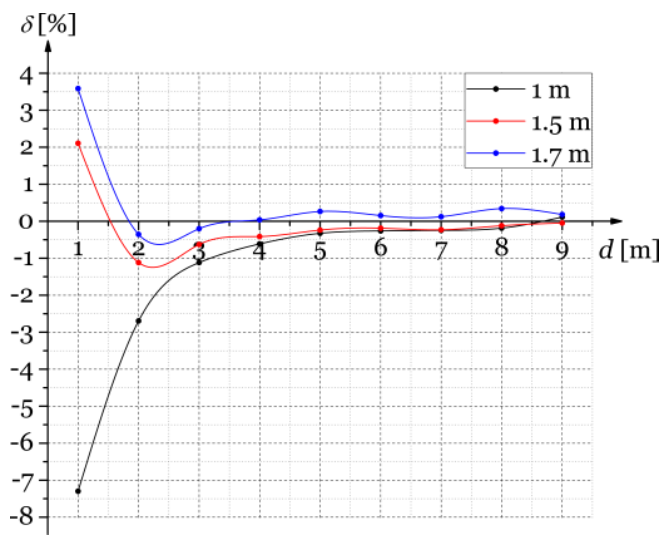

Figure 12. Percent errors for various distances between the probe and the operator and different heights of the probe

As previously stated, the results given in Table 3 are determined on the basis of 10 measurements of electric field strength, which were performed at each specific distance and height, as the average value of these 10 results. For each distance and height the standard deviation of the results $\sigma$ is calculated as:

$$
\sigma=\sqrt{\frac{\sum_{i=1}^{N}\left(E_{i}-E_{\text {avg }}\right)^{2}}{N}}
$$

where symbols denote the following:

$N=10$ - number of measurements performed at each distance and height,

$E_{i}(i=1,2, \ldots 10)$-values of electric field strength obtained at the same distance and height.

$E_{a v g}$ - average value of electric field strength obtained for each distance and height. Table 4.

The results of standard deviation are presented in

Table 4. Standard deviation of results obtained for various distances between the measuring probe and the operator and different heights of the measuring probe

\begin{tabular}{|c|c|c|c|}
\hline \multirow{2}{*}{$d[\mathrm{~m}]$} & \multicolumn{3}{|c|}{$\sigma$} \\
\cline { 2 - 4 } & $h=1 \mathrm{~m}$ & $h=1.5 \mathrm{~m}$ & $h=1.7 \mathrm{~m}$ \\
\hline 1 & 0.006 & 0.005 & 0.003 \\
\hline 2 & 0.003 & 0.001 & 0.001 \\
\hline 3 & 0.001 & 0.002 & 0.001 \\
\hline 4 & 0.004 & 0.002 & 0.003 \\
\hline 5 & 0.001 & 0.002 & 0.002 \\
\hline 6 & 0.003 & 0.002 & 0.002 \\
\hline 7 & 0.002 & 0.001 & 0.005 \\
\hline 8 & 0.002 & 0.003 & 0.002 \\
\hline 9 & 0.001 & 0.002 & 0.003 \\
\hline 10 & 0.003 & 0.001 & 0.002 \\
\hline
\end{tabular}

On the basis of the results presented in Table 4 it can be concluded that the values of standard deviation are very small due to the fact that the 10 obtained results of electric field strength measured at each distance and height are very similar to each other.

\section{CONCLUSION}

The results presented in this paper show that the presence of the operator can have a significant influence on the measured values of electric field strength. This influence decreases with the increase of distance between the operator and the measuring probe. At distances of $5 \mathrm{~m}$ and greater, the values of electric field strength measurement error are lower than $0.8 \%$ regardless of the height at which the measuring probe is placed. At distances of $10 \mathrm{~m}$ and greater, this influence can be considered negligible. When measurements are performed at shorter distances, the influence of the operator has to be taken into account when calculating the expanded measurement uncertainty. In order to decrease this influence and to determine the distance at which it becomes negligible, after placing the measurement probe at the selected measurement point the operator should take readings while moving away from the probe and stop moving when the readings become stable.

\section{REFERENCES}

1. J. Di Placido et al., "Analysis of the proximity effects in electric field measurements", IEEE Trans. Power App. Syst., vol. PAS-97, no. 6, pp. 2167 - 2177, Nov-Dec. 1978.

DOI: 10.1109/TPAS.1978.354720

2. Technical guide for measurement of low frequency electric and magnetic fields near overhead power lines, WG C4.203, CIGRE, Apr. 2009.

3. Measurement of $D C$ magnetic, $A C$ magnetic and $A C$ electric fields from $1 \mathrm{~Hz}$ to $10 \mathrm{oHHz}$ with regard to exposure of human beings - Part 1: Requirements for measuring instruments, EN 61786-1:2014, Jul. 31, 2014.

4. Measurement of DC magnetic, $A C$ magnetic and $A C$ electric fields from $1 \mathrm{~Hz}$ to $10 \mathrm{kHz}$ with regard to exposure of human beings - Part 2: Basic standard for measurements, IEC 61786-2:2014, Dec. 11, 2014.

5. Electric and magnetic field levels generated by AC power systems-measurement procedures with regard to public exposure, EN 62110:2009, Aug. 31, 2009.

6. IEEE standard procedures for measurement of power frequency electric and magnetic fields from AC power lines, IEEE 644-1994, Dec. 13, 1994. 